\title{
$\beta$-Arrestin-2 regulates the development of allergic asthma
}

\author{
Julia K.L. Walker, ${ }^{1}$ Alan M. Fong, ${ }^{1}$ Barbara L. Lawson, ${ }^{1}$ Jordan D. Savov, ${ }^{1}$ \\ Dhavalkumar D. Patel, ${ }^{1}$ David A. Schwartz, ${ }^{1}$ and Robert J. Lefkowitz ${ }^{1,2}$ \\ ${ }^{1}$ Department of Medicine, and \\ ${ }^{2}$ Howard Hughes Medical Institute, Duke University Medical Center, Durham, North Carolina, USA
}

\begin{abstract}
Asthma is a chronic inflammatory disorder of the airways that is coordinated by Th2 cells in both human asthmatics and animal models of allergic asthma. Migration of Th2 cells to the lung is key to their inflammatory function and is regulated in large part by chemokine receptors, members of the seven-membrane-spanning receptor family. It has been reported recently that $\mathrm{T}$ cells lacking $\beta$-arrestin- 2 , a $G$ protein-coupled receptor regulatory protein, demonstrate impaired migration in vitro. Here we show that allergen-sensitized mice having a targeted deletion of the $\beta$-arrestin- 2 gene do not accumulate $T$ lymphocytes in their airways, nor do they demonstrate other physiological and inflammatory features characteristic of asthma. In contrast, the airway inflammatory response to LPS, an event not coordinated by Th2 cells, is fully functional in mice lacking $\beta$-arrestin- 2 . $\beta$-arrestin-2-deficient mice demonstrate OVA-specific IgE responses, but have defective macrophage-derived chemokine-mediated $\mathrm{CD}^{+} \mathrm{T}$ cell migration to the lung. This report provides the first evidence that $\beta$-arrestin- 2 is required for the manifestation of allergic asthma. Because $\beta$-arrestin2 regulates the development of allergic inflammation at a proximal step in the inflammatory cascade, novel therapies focused on this protein may prove useful in the treatment of asthma.
\end{abstract}

J. Clin. Invest. 112:566-574 (2003). doi:10.1172/JCI200317265.

\section{Introduction}

Asthma is a complex inflammatory disease that afflicts nearly 15 million Americans. Despite research advances, the worldwide prevalence, morbidity, and mortality of asthma have increased over the last two decades (1-3). In humans, the hallmark feature of allergic asthma is the abnormal expansion in the lung of Th cells that produce Th2 cytokines. This pathological event leads to the symptoms of asthma including airway inflammation, airway hyperresponsiveness, reversible airflow obstruction, and airway remodeling. Like other immune cells, $\mathrm{T}$ cells are functionally dependent on their ability to migrate, localize within tissues, and interact with other immune cells (4). Chemotaxis, the process by which immune cells migrate, is mediated by chemokine activation of chemokine receptors (5).

Chemokine receptors are part of the enormous family of heptahelical cell surface receptors known as G protein-coupled receptors (GPCRs) (6). These receptors transduce extracellular signals into intracellular events by activating heterotrimeric $G$ proteins. The

Received for publication October 30, 2002, and accepted in revised form June 3, 2003.

Address correspondence to: Robert J. Lefkowitz, Department of Medicine, Duke University Medical Center, Box 3821, Durham, North Carolina 27710, USA. Phone: (919) 684-2974; Fax: (919) 684-8875; E-mail: lefko001@receptor-biol.duke.edu. Conflict of interest: The authors have declared that no conflict of interest exists.

Nonstandard abbreviations used: $G$ protein-coupled receptor (GPCR); stromal cell-derived factor- $1 \alpha($ SDF- $1 \alpha) ; \beta$-arrestin2 -deficient ( $\beta$ arr 2-/-) macrophage-derived chemokine (MDC); honestly significant difference (HSD). dissociation of these $\mathrm{G}$ protein subunits activates cell signaling systems such as adenylate cyclases, phospholipases, and ion channels, which ultimately results in a physiological response. In the case of chemokine receptors, at least one of these physiological responses is cell migration.

Like other GPCRs, chemokine receptor function is regulated by $\beta$-arrestin proteins. $\beta$-arrestins, members of the arrestin family of proteins, are designated $\beta$ arrestin- 1 or $\beta$-arrestin- 2 , are ubiquitously expressed, and regulate GPCR function through multiple mechanisms (7-9). As their name suggests, $\beta$-arrestin proteins were originally discovered to "arrest" G protein-mediated cell signaling events (10). Since that time, our understanding of the mechanisms by which $\beta$-arrestin modulates GPCR function has expanded considerably. In addition to their classical role, $\beta$-arrestin proteins also act as adapters that couple GPCRs to a clathrin-coated pit endocytic mechanism and as scaffolds that link GPCRs to a second wave of cell signaling via MAPK and other signaling pathways.

In vitro studies have shown that lymphocytes devoid of $\beta$-arrestin- 2 and human embryonic kidney 293 cells with suppressed expression of $\beta$-arrestin- 2 demonstrate impaired migration toward the chemotactic factor stromal cell-derived factor- $1 \alpha$ (SDF-1 $\alpha$ ), also known as CXCL12 $(11,12)$. Although $\beta$-arrestin-2 is essential to the normal migration of immune cells in vitro, the ability of $\beta$-arrestin- 2 to mediate immune cell chemotaxis in vivo has not been tested.

Because chemotaxis is crucial to the process of inflammation, we theorized that mice lacking $\beta$-arrestin- 2 might be protected from developing allergic-asthmatic inflammation. To model allergic asthma in mice we 
used a standard method consisting of sensitization and challenge to OVA (13). This mouse model of allergic asthma mimics several features of human asthma.

\section{Methods}

Animals. Male and female $\beta$-arrestin-2-deficient $\left({\left.\text { (arr } 2^{-/-}\right)}\right.$(14) and littermate WT mice (backcrossed for six generations onto the C57BL/ 6 background) were used for all experiments at $8-12$ weeks of age. All experiments were conducted in accordance with NIH guidelines for the care and use of animals and with approval from the Duke University Animal Care and Use Committee.

Immunization and airway challenge. Mice were immunized intraperitoneally on days 0,7 , and 14 with $10 \mu \mathrm{g}$ grade V OVA (Sigma-Aldrich, St. Louis, Missouri, USA) adsorbed to $200 \mu \mathrm{g}$ of alum adjuvant (Pierce Biotechnology Inc., Rockford, Illinois, USA) diluted in saline. Sham-immunized animals received $200 \mu \mathrm{g}$ of saline-diluted alum intraperitoneally. Secondary challenge consisted of a 60-minute exposure to $1 \%$ (wt/vol) OVA in saline on days 21, 22, and 23. All mice were exposed to aerosol in a 60-1 exposure chamber connected to the outlet of a six-jet atomizer that delivered an aerosol of particles with a mean diameter of $0.3 \mu \mathrm{m}$ (TSI Inc., St. Paul, Minnesota, USA). The term "OVA treatment" is used hereafter to refer to mice treated according to the OVA sensitization and OVA aerosol challenge protocol described above.

Endotoxin exposures. LPS for aerosolization was purchased as lyophilized purified Escherichia coli 0111:B4 (Sigma-Aldrich). LPS was solubilized in sterile saline to a concentration of $5 \mathrm{mg} / \mathrm{ml}$, stored at $-20^{\circ} \mathrm{C}$, and diluted further in saline to the appropriate concentration on the day of the experiment. LPS was aerosolized with a six-jet atomizer (TSI Inc.) that generated particles with a mean diameter of $0.3 \mu \mathrm{m}$, and directed into a 60-1 exposure chamber for 2.5 hours. At regular intervals, LPS concentrations were determined by sampling the aerosol through a side port on the chamber. Endotoxin concentrations were assayed with the chromogenic Limulus amebocyte lysate assay (BioWhittaker Inc., Walkersville, Maryland, USA) as previously described (15). The average endotoxin concentration used was $5.53 \pm 0.5 \mu \mathrm{g} / \mathrm{m}^{3}$.

Airway responsiveness. The day after the final aerosol challenge, airway responsiveness to methacholine was measured as previously described (16). In brief, mice were anesthetized with an intraperitoneal injection of pentobarbital sodium $(60 \mathrm{mg} / \mathrm{kg})$ diluted $50 \%$ with saline and then surgically prepared with a tracheal cannula and a jugular vein catheter. Mice were paralyzed with doxacurium chloride $(0.25 \mathrm{mg} / \mathrm{kg})$ and ventilated with $100 \%$ oxygen at a constant volume of $8-10 \mathrm{ml} / \mathrm{kg}$ and a frequency of 125 breaths $/ \mathrm{min}$. These ventilator settings resulted in an average resting peak airway pressure of $7.8 \pm 0.2 \mathrm{~cm} \mathrm{H}_{2} \mathrm{O}$ and have been previously shown to provide normal arterial blood gases. Measurement of airway pressure was made at a side port of the tracheal cannula connected to a Validyne differential pressure transducer (Validyne Engineering, Northridge, California, USA). The time-integrated change in peak airway pressure, or airway pressure time index (17), was calculated for a 30second period beginning immediately after methacholine injection.

Whole-lung lavage. After in vivo measurements, mice were sacrificed by sodium pentobarbital overdose. Lungs were lavaged as previously described (15). Differential cell counts were performed on cytospin preparations (Cytospin 2; Thermo Shandon, Pittsburgh, Pennsylvania, USA) stained using Hema-3 staining kit (Fisher Scientific, Springfield, New Jersey, USA) and 200 cells were classified using standard morphologic criteria. Lavage fluid cytokine levels were determined in lavage fluid using commercially available cytokine ELISA kits (Quantikine; R\&D Systems Inc., Minneapolis, Minnesota, USA). The detection limits were as follows: IL-4 $(2 \mathrm{pg} / \mathrm{ml})$, IL-5 (7 pg/ml), IL-13 (1.5 pg/ml), IL-12 (< $4 \mathrm{pg} / \mathrm{ml})$, IFN- $\gamma(<2 \mathrm{pg} / \mathrm{ml})$, and macrophage-derived chemokine $(\mathrm{MDC})(<5 \mathrm{pg} / \mathrm{ml})$.

Serum Ig titers. At three timepoints in the sensitization protocol (day 10, day 17, and after in vivo measurements on day 24), blood was harvested from the inferior vena cava of $\beta a r r 2^{-/-}$and WT mice. Serum was separated by centrifugation and stored at $-20^{\circ} \mathrm{C}$ until analyzed. OVA-specific serum IgE, $\operatorname{IgG}_{1}$, and $\operatorname{IgG}_{2 \mathrm{a}}$ levels were determined using ELISA methodology and geometric mean titer analysis. Briefly, 96-well plates (NUNC MaxiSorp; Nalge Nunc International, Neerijse, Belgium) were coated with $100 \mu \mathrm{l} /$ well of 100 $\mu \mathrm{g} / \mathrm{ml}$ OVA (Sigma-Aldrich) in $0.1 \mathrm{M}$ carbonate coating buffer ( $\mathrm{pH} 9.6)$ and incubated overnight at $4{ }^{\circ} \mathrm{C}$. The wells were washed with $0.5 \%$ Tween $20 / \mathrm{PBS}$ and blocked with $1 \%$ BSA/PBS, which also served as the assay diluent. After 1.5 hours, wells were washed three times and samples (serially diluted 1:2 twelve times, beginning with $1: 64)$ were added across the plate and incubated for 1.5 hours at $37^{\circ} \mathrm{C}$. After washing, the primary antibody (sheep anti-mouse IgE from Calbiochem-Novabiochem Corp., San Diego, California, USA) was added and samples were incubated a further 1.5 hours, washed, and incubated a second time with the detection antibody (peroxidase-conjugated rabbit anti-sheep IgG from Calbiochem-Novabiochem Corp.). For detection of OVA-IgG $\mathrm{I}_{1}$, the primary antibody was biotin-conjugated anti-mouse IgG $_{1}$ with avidin-HRP at $2.5 \mu \mathrm{g} / \mathrm{ml}$ (A3151; Sigma-Aldrich). For detection of OVA-IgG $\mathrm{I}_{2 \mathrm{a}}$, the primary antibody was HRP-conjugated anti-mouse $\operatorname{IgG}_{2 a}$ (BD Pharmingen, San Diego, California, USA). After a further wash, all plates were developed with tetramethylbenzidine substrate solution, stopped with $2 \mathrm{~N} \mathrm{H}_{2} \mathrm{SO}_{4}$, and read at $450 \mathrm{~nm}$. Naive serum from nonsensitized C57BL/6J mice was assayed on each plate to calculate a standard curve, and titers were calculated at twofold over the asymptote of the naive curve. 
Isolation of lymphocytes. All lymphocyte isolation was carried out in polypropylene tubes. Spleens were isolated from OVA-treated mice and disrupted in a dounce homogenizer in $1 \mathrm{ml}$ RPMI 1640 medium (Invitrogen Corp., Gaithersburg, Maryland, USA). Following centrifugation at $370 \mathrm{~g}$ for $10 \mathrm{~min}$ utes, rbc's were lysed in lysis buffer $\left(0.14 \mathrm{M} \mathrm{NH}_{4} \mathrm{Cl}\right.$ and $0.017 \mathrm{M}$ Tris, $\mathrm{pH}$ 7.4) and the cells were pelleted. The cells were washed in RPMI, filtered through a $70-\mu \mathrm{m}$ BD Falcon strainer (Becton, Dickinson and Co.), and counted.

Lungs were isolated and disrupted in HBSS containing $0.5 \mathrm{U} / \mathrm{ml}$ heparin through a 200 -gauge stainless steel mesh. Lymphocytes from either OVA-treated WT or OVA-treated $\beta a r r 2^{-/-}$mice were pooled. The cells were centrifuged at $370 \mathrm{~g}$ for 10 minutes at $4^{\circ} \mathrm{C}$ and resuspended in $15 \mathrm{ml}$ of a 33\% Percoll solution (Sigma-Aldrich) diluted in HBSS containing 100 $\mathrm{U} / \mathrm{ml}$ heparin. The cells were centrifuged at $500 \mathrm{~g}$ for 15 minutes at room temperature. The pelleted cells were resuspended in lysis buffer to remove red blood cells. The cells were then washed in HBSS, resuspended in RPMI containing $10 \% \mathrm{FBS}$, and counted.

Chemotaxis assays. Splenocytes $\left(1 \times 10^{6}\right)$ or lung lymphocytes $\left(1 \times 10^{5}\right)$ were placed in $100 \mu \mathrm{l}$ RPMI containing $10 \% \mathrm{FBS}$ in the upper chamber of a Transwell insert ( $6.5 \mathrm{~mm}$ diameter, $5-\mu \mathrm{m}$ pore size; Corning Costar Corp., Acton, Massachusetts, USA). The lower chamber contained $100 \mathrm{nM}$ MDC (R\&D Systems Inc.) in $600 \mu \mathrm{l} \mathrm{RPMI}$ prepared with $10 \% \mathrm{FBS}$. After incubation at $37^{\circ} \mathrm{C}$ for 90 minutes, the migrated cells were collected from the lower chamber. The cells were stained with the following antibodies: 17A2-FITC (anti-CD3, BD Pharmingen), GK1.5-phycoerythrin (anti-CD4, BD Pharmingen), and anti-CD45R-tricolor (Caltag Laboratories Inc., Burlingame, California, USA). Cells were then analyzed using a Coulter Epics XL flow cytometer (Coulter Electronics Ltd., Hialeah, Florida, USA). The chemotactic index was calculated as the number of cells migrating toward $\mathrm{MDC} /$ number of cells migrating to medium alone. All assays were performed in duplicate. $\beta a r r 2^{-/-}$mice and their littermate-matched controls were tested simultaneously.

Histopathology. Immediately after collection of lavage fluid, ice-cold 4\% paraformaldehyde (Fisher Scientific Co., Pittsburgh, Pennsylvania, USA) in $1 \times \mathrm{PBS}(\mathrm{pH}$ 7.4) was instilled through the tracheal cannula at a constant pressure of $25 \mathrm{~cm} \mathrm{H}_{2} \mathrm{O}$ to inflation-fix the lung. Specimens were immersed in $4 \%$ paraformaldehyde at $4^{\circ} \mathrm{C}$ overnight and dehydrated in a graded series of ethanol solutions. Tissue was embedded in paraffin. Sections were cut at $5 \mu \mathrm{m}$ thickness and mounted onto positively charged slides (Super Frost Plus; Fisher Scientific Co.). For determination of inflammatory cells, H\&E-stained slides were semiquantitatively scored in a blinded fashion. For determination of $\mathrm{CD}^{+} \mathrm{T}$ cells, tissue sections underwent a high-temperature antigen-unmasking procedure as follows. After dewaxing and rehydration, the sections were immersed in 1.61 of $1 \mathrm{mM}$ EDTA, $\mathrm{pH} 8.0$, in a pressure cooker that was then closed and slowly, over a period of 3-4 minutes, brought to boiling temperature. After a total time of 5 minutes, the pressure cooker was cooled under running tap water and opened, and the slides were transferred to PBS ( $\mathrm{pH}$ 7.5) and rested at room temperature for 5 minutes. Endogenous peroxidase was destroyed with $0.3 \%$ $\mathrm{H}_{2} \mathrm{O}_{2}$ for 30 minutes at room temperature, followed by a rinse in blocking normal rabbit serum. The primary antibody used was a rat monoclonal anti-CD3 antibody from Novocastra Laboratories Ltd. (Newcastle, United Kingdom). Slides were incubated with either active antibody $(1: 250)$ or with normal rat $\operatorname{IgG}$ as a negative control. The secondary antibody was biotin-conjugated rabbit anti-rat IgG (Vector Laboratories Inc., Burlingame, California, USA), addition of which was followed by treatment with standard avidin-biotin HRP. Peroxidase activity was detected with 3,3'-diaminobenzidine (DAB; Vector Laboratories Inc.) and hydrogen peroxide, after which a hematoxylin counterstain was performed.

Statistical analysis. Multivariate ANOVA was used to determine differences in airway responsiveness. A Student $t$ test was used to determine differences when only two experimental groups existed. Otherwise, a one-way ANOVA, in combination with a Tukey honestly significant difference (HSD) post-hoc test, was used to determine differences among groups. For all tests, $P<0.05$ was considered significant.

\section{Results}

To examine the role of $\beta$-arrestin- 2 in the pathogenesis of asthma, we used an OVA model of allergic asthma and an endotoxin model of nonallergic asthma. We measured physiological and biological variables including airway responsiveness, airway inflammatory cell infiltration, $T$ cell chemotaxis, cytokine levels in whole-lung lavage fluid, and serum Ig levels.

Airway responsiveness. OVA treatment resulted in a dramatic increase in airway responsiveness in WT mice (Figure 1 ) as measured by airway pressure time index. In marked contrast, $\beta a r r 2^{-/-}$mice treated with OVA ( $\beta a r r 2^{-/}$-OVA mice) showed no such increase in airway responsiveness compared with either WT-alum or Barr2 $2^{-/}$-alum (control) mice.

Lung inflammation. Histological analysis showed that only mild extravasation of inflammatory cells, including $\mathrm{CD}^{+} \mathrm{T}$ lymphocytes, occurred in the airways of Barr $2^{-/}$mice treated with OVA, whereas severe cellular infiltration occurred in the interstitium of WTOVA mice (Figure 2, a and b). Quantitation of $\mathrm{CD}^{+}$ cells per mm of basement membrane or $\mathrm{CD} 4^{+}$cells harvested from lung show that $\beta a r r 2^{-/-}$mice experience significantly reduced $\mathrm{T}$ lymphocyte infiltration into the lung (Table 1). Differential cell counts from lavage fluid supported the histological data revealing that lymphocyte and eosinophil infiltration into the 


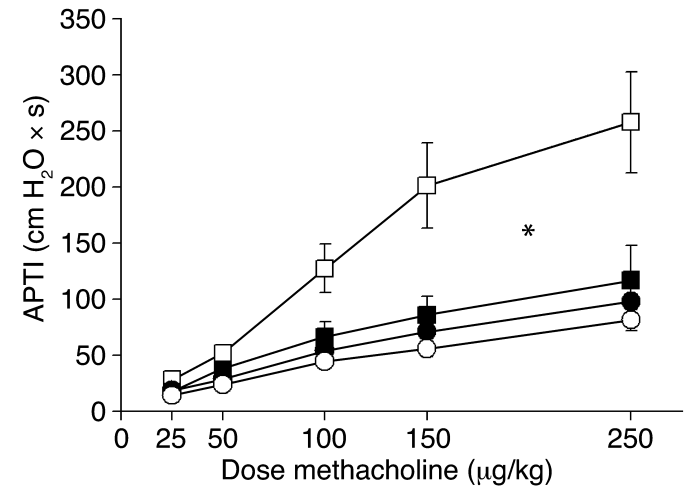

Figure 1

Effect of OVA treatment on airway responsiveness. Airway responsiveness to methacholine, defined by the time-integrated change in peak airway pressure, or airway pressure time index (APTI), was measured for Barr2 $2^{-/}$(circles) and WT (squares) mice treated with either alum (filled symbols) or OVA (open symbols). Data are mean \pm SEM; $n=9-12$ mice per group. ${ }^{*}$ Effect of OVA treatment was significantly different between WT and $\beta a r r 2^{-/-}$mice. $P<0.05$.

lungs of $\beta a r r 2^{-/-}$-OVA mice was markedly reduced compared with WT-OVA mice and was not different from that in alum-treated control mice of either genotype (Figure $2 \mathrm{c}$ ). The lack of $\mathrm{T}$ lymphocytes in the lung of $\beta a r r 2^{-1-}$-OVA mice suggests that the migration of $\mathrm{T}$ cells to the lung is impaired in the absence of $\beta$-arrestin- 2 .

Cytokine levels. Activated $\mathrm{T}$ cells migrate to the lungs and release inflammatory cytokines to orchestrate the allergic inflammatory response. Consistent with the demonstrated lack of lymphocytes in the airways of Barr $2^{-/-}$OVA mice was their diminished level of Th2 cytokines. Analysis of lavage fluid from WT-OVA mice showed a significant increase in the levels of IL-4, IL-5, and IL-13 relative to the respective cytokine level in lavage fluid from $\beta a r r 2^{-/-}$-OVA mice and alum controls (Figure 3a). To determine whether $\beta a r r 2^{-/-}$mice have a Th1-skewed response that might inhibit the development of Th2 lymphocytes, we measured Th1type cytokines in lung lavage fluid (18). Levels of IL-12 and IFN- $\gamma$ were not different between WT and $\beta a r r 2^{--}$ mice, and the level of these cytokines was unaffected by OVA treatment (Figure 3b).

Ig production. The absence of the classic features of a Th2-mediated asthmatic response in OVA-treated $\beta a r r 2^{-/-}$mice indicates that $\beta$-arrestin- 2 exerts its regulatory effect early in the progression of allergic asthma. $\beta$-Arrestin- 2 may regulate the handling of aeroallergen, a series of events that occurs prior to, and is necessary for, $T$ cell stimulation and allergenspecific Ig production. However, the serum levels of OVA-specific IgE and OVA-specific $\operatorname{IgG}_{1}$ were significantly elevated in $\beta a r r 2^{-/-}$-OVA mice, and the magnitude of this antigen-specific antibody production was not significantly different from the response observed in WT-OVA mice (Figure 4, a and b). Thus, Barr $2^{-/-}$mice are competent in their ability to present antigen, to generate antigen-specific $\mathrm{T}$ cell responses, and to undergo Ig isotype switching. Measurement of $\operatorname{IgG}_{2 a}$, a serum Ig typical of a Th1-type response, was not different between WT and $\beta a r r 2^{-/-}$ mice (Figure 5, a and $\mathrm{b}$ ). These data show that the lack of a Th2-type response in $\beta a r r 2^{-/-}$mice is not due to enhanced induction of the Th1 arm of the Th cell pathway for development.

$\mathrm{CD}^{+} \mathrm{T}$ cell chemotaxis. In allergic asthma, MDC is a potent Th2 cell chemoattractant produced by activated lung macrophages, airway smooth muscle cells,

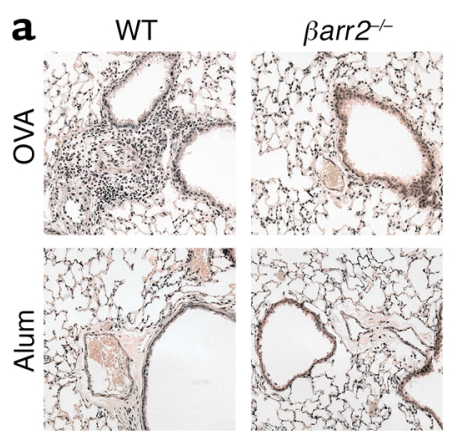

b

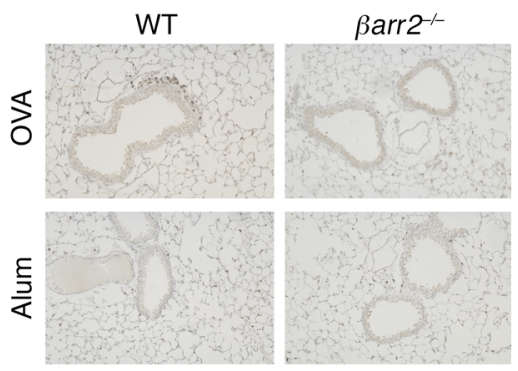

c

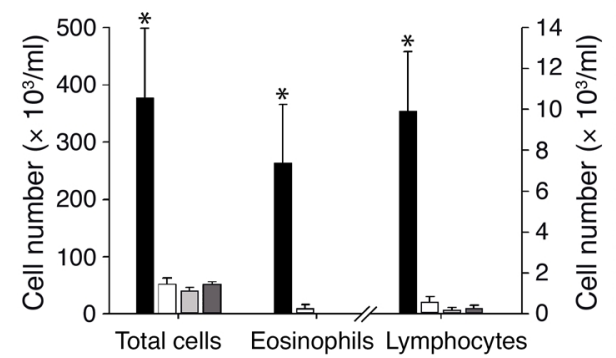

\section{Figure 2}

Effect of OVA treatment on airway inflammation. (a) Effect of genotype and OVA treatment on lung inflammation evaluated by histological analysis of lung sections. Lung sections from WT-alum (lower left) and Barr $2^{-/}$-alum mice (lower right) appeared normal with no inflammatory cell infiltration. Lung sections from WT-OVA mice (upper left) showed severe cellular infiltration in the interstitium. Lung sections from $\beta a r 2^{-/-}$-OVA mice (upper right) showed mild extravasation of inflammatory cells in the interstitium. Representative histological sections are shown ( $n=8-11$ mice per group). (b) Representative images of cross-sectioned airways together with peribronchovascular connective tissue are shown. CD3 ${ }^{+} \mathrm{T}$ cells were counted in the subtended bronchovascular interstitium. OVA-treated WT mice showed an increased number of $\mathrm{CD}^{+} \mathrm{T}$ cells in the peribronchovascular zone relative to alum-treated mice. No such infiltration of $\mathrm{CD}^{+} \mathrm{T}$ cells was observed in OVA-treated $\beta a r 2^{-1-}$ mice. (c) Effect of genotype and OVA treatment on lung inflammation assessed by identification of cells harvested from whole-lung lavage. Black bars represent WT-OVA mice; white bars represent $\beta a r r 2^{-/-}-$OVA mice; light gray bars represent WT-alum mice; dark gray bars represent $\beta a r r 2^{-/-}$-alum mice. Data are mean $\pm \mathrm{SEM} ; n=9-12$ mice per group. ${ }^{*} P<0.05$ versus all other groups. 
Table 1

Quantitation of T lymphocytes in the lung

\begin{tabular}{|c|c|c|}
\hline & $\begin{array}{c}\mathrm{CD}^{+} \text {cells per mm } \\
\text { basement membrane }\end{array}$ & $\begin{array}{l}\mathrm{CD}^{+} \mathrm{T} \text { cells } \\
\text { harvested from lung }\end{array}$ \\
\hline WT-OVA & $31.04 \pm 1.36^{*}$ & $21,400 /$ lung \\
\hline Barr2-/--OVA & $2.08 \pm 1.57$ & $6,900 /$ lung \\
\hline WT-alum & $2.96 \pm 0.85$ & \\
\hline ßarr2-/--alum & $2.21 \pm 0.74$ & \\
\hline
\end{tabular}

Using calibrated digital images, the perimeter of the bronchiolar basal lamina of each histological profile (represented in Figure $2 \mathrm{~b}$ ) was traced and the length was measured. The results were expressed as the number of $\mathrm{CD}^{+} \mathrm{T}$ cells per $\mathrm{mm}$ of airway basal lamina for each profile. To quantitate the number of CD4 ${ }^{+} \mathrm{T}$ cells, lungs from OVA-treated mice were processed and cells were identified using GK1.5-phycoerythrin (anti-CD4) and FACS analysis. The mean \pm SEM for each treatment/genotype group is shown; $n=7-10$ mice per group. ${ }^{*} P<0.05$ versus all other groups.

bronchiolar epithelial cells, and by Th2 cells themselves (5). To investigate whether $\mathrm{CD}^{+} \mathrm{T}$ cell migration to the lung is impaired in $\beta a r r 2^{-/-}$mice, we tested the ability of splenocytes, thoracic lymph node cells, and lung lymphocytes from OVA-treated WT and $\beta a r r 2^{-/-}$mice to respond to MDC. Only lung lymphocytes, and not spleen or lymph node T cells (data not shown), migrated toward MDC. While CD4 ${ }^{+} \mathrm{T}$ cells harvested from lung of OVA-treated WT mice migrated well toward MDC, $\mathrm{CD} 4^{+} \mathrm{T}$ cells lacking $\beta$ arrestin- 2 were significantly impaired in their migration toward MDC (Figure 6a). MDC levels in lavage fluid were significantly elevated in OVA-treated WT mice, but not in similarly treated $\beta a r r 2^{-/-}$mice (Figure $6 \mathrm{~b})$. These data support the notion that $\beta$ arrestin- 2 positively regulates MDC-mediated $\mathrm{CD}^{+}$ $\mathrm{T}$ cell migration to the lung in OVA-treated mice. However, $\beta$-arrestin- 2 may alternatively, or additionally, regulate $\mathrm{CD} 4^{+} \mathrm{T}$ cell migration in response to a chemokine other than MDC.

Nonallergic asthma model. To further investigate the specificity of the impaired asthmatic response in Barr $2^{-/-}$mice, we subjected mice to a model of endotoxin-mediated asthma, or nonallergic asthma. Endotoxin, an LPS, is a major component of the

\section{Figure 3}

Effect of genotype and OVA treatment on lung cytokine release in whole-lung lavage fluid. (a) Cytokines associated with a Th2-type response were significantly elevated in WT-OVA mice relative to Barr ${ }^{-1-}$-OVA mice and alum-treated mice of either genotype. Black bars represent WT-OVA mice; white bars represent $\beta a r 2^{-/-}-$OVA mice. Cytokine levels in alum-treated WT and alum-treated $\beta a r r 2^{-/-}$ mice were not different and therefore were combined as shown by gray bars. Data are mean \pm SEM calculated from three independent experiments; $n=11-19$ mice per group. ${ }^{*} P<0.05$ versus all other groups. (b) Cytokines associated with a Th1-type response were not significantly elevated by OVA treatment and were similar for WT and $\beta a r r 2^{-/-}$mice. Black bars represent WT-OVA mice; white bars represent $\beta a r 2^{-/-}$-OVA mice. Light gray bars represent alum-treated WT mice; dark gray bars represent $\beta a r r 2^{-/-}$mice. Data are mean \pm SEM calculated from two to three independent experiments; $n=7-13$ mice per group. outer cell membrane of all gram-negative bacteria, and even small amounts of this molecule are immune-stimulatory (19). Subjects with endotoxic asthma demonstrate lung neutrophilic inflammation and airway hyperresponsiveness, and this response is coordinated by alveolar macrophages and epithelial cells rather than T cells (20). Both WT and Barr $2^{-/-}$mice exposed to aerosolized LPS developed lung neutrophilic inflammation and increased airway responsiveness (Figure 7 , $a$ and $b$ ). Thus, there is no general impairment of lung inflammatory processes or in the ability of airways to respond to methacholine in $\beta a r r 2^{-/-}$mice.

\section{Discussion}

When treated with OVA, WT mice develop symptoms of allergic asthma. In stark contrast, these symptoms, including airway inflammation and airway hyperresponsiveness, do not appear in similarly treated $\beta a r r 2^{-/}$mice. These results suggest that $\beta$-arrestin- 2 is essential to the development of allergic asthma and that it exerts its regulatory effect at a proximal step in the inflammatory cascade.

Numerous immune cell types, including APCs, T lymphocytes, B lymphocytes, eosinophils, and mast cells, interact in a highly coordinated fashion to respond to allergens. Although the nature and sequence of these interactions are not entirely delineated, the infiltration of activated Th 2 cells into the lung is a primary pathological event underlying allergic asthma. Without these cells, the symptoms of asthma, including airway inflammation, airway hyperresponsiveness, and reversible airflow obstruction, do not occur (21-23).

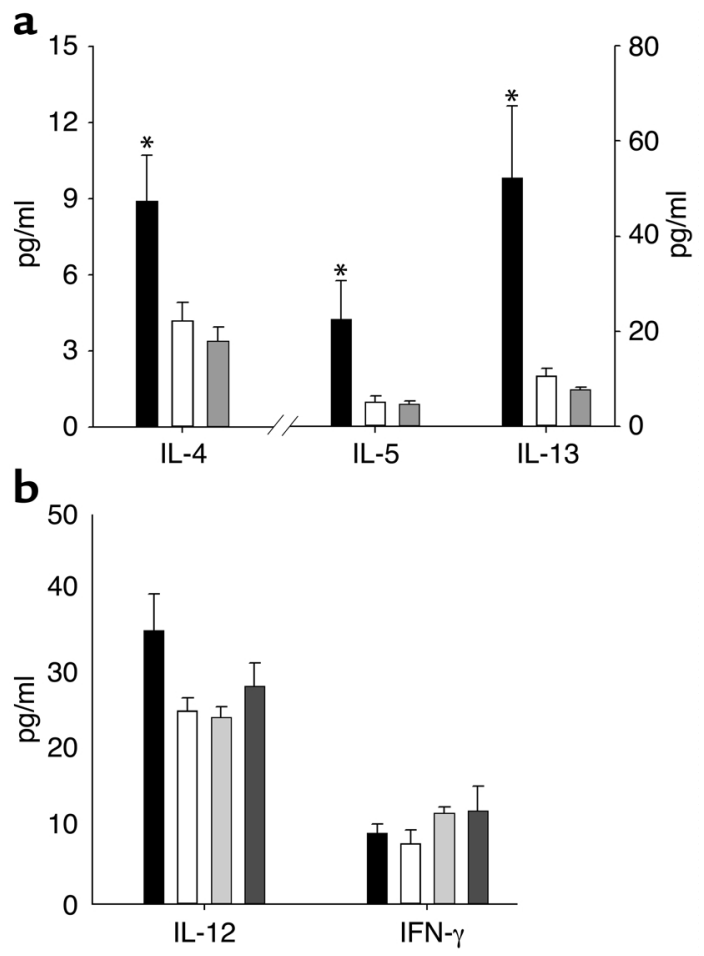




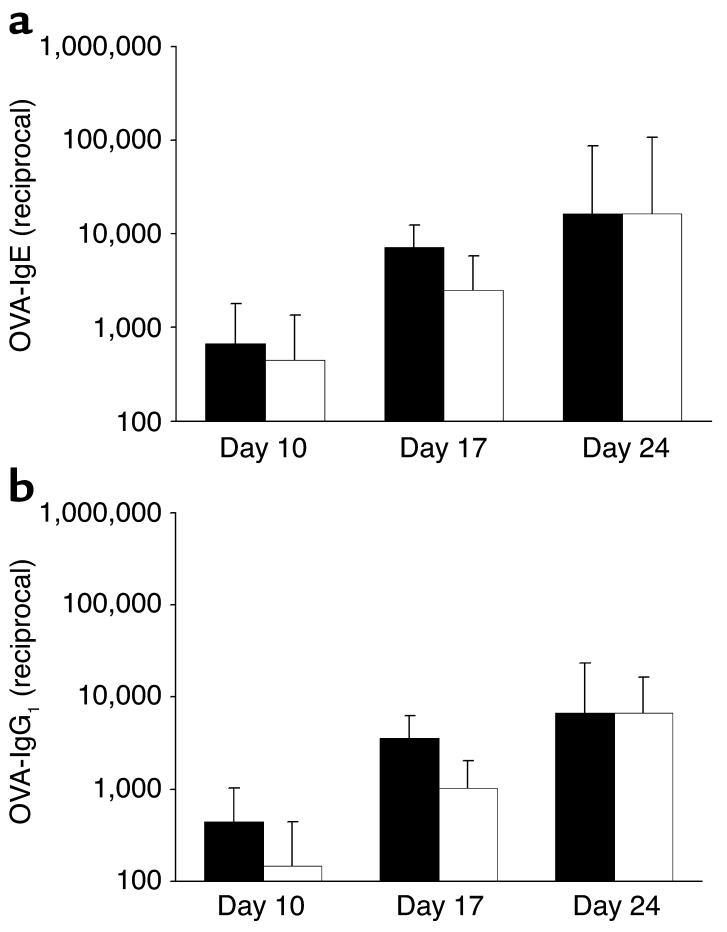

The initial event in the development of allergic asthma is the processing of inhaled allergens. This involves the capture, modification, and presentation of allergen to T and B cells (24). Once activated, T cells proliferate and differentiate to a Th2 phenotype defined by the release of type 2 cytokines (IL-4, IL-5, IL-6, IL-9, IL-10, and IL-13). Release of these cytokines at germinal centers within peripheral lymphoid tissue supports B cell-mediated production of allergen-specific antibodies $(25,26)$. In addition, type 2 cytokines released from $T$ cells that have migrated to the lung activate and recruit mast cells and eosinophils, the primary effector cells of the allergic asthmatic response (1).

Our study shows that antigen processing, presentation, and activation of $\mathrm{T}$ cells are intact in $\beta a r r 2^{-/-}$ mice since their serum levels of OVA-specific IgE and $\mathrm{IgG}_{1}$ are comparable to those in WT mice and are significantly elevated compared with alum-treated mice. Although there is a trend for a slight delay in the kinetics of the Ig response in OVA-treated $\beta a r r 2^{-/-}$ mice, the impact of this on the physiological and bio-

\section{Figure 5}

$\operatorname{lgG}_{2 a}$ production. (a) Total serum $\operatorname{lgG}_{2 a}$ levels were not different between WT-OVA mice (black bars) and Barr2 ${ }^{-/-}$-OVA mice (white bars) at day 10,17 , or 24 . Similarly, there was no difference in $\lg _{2 a}$ levels in serum from alum-treated WT (light gray bars) and alumtreated $\beta a r r 2^{-/-}$mice (dark gray bars). Data are mean \pm SEM calculated from three independent experiments; $n=4-14$ mice per group. (b) OVA-specific $\operatorname{lgG}_{2 a}$ measurements were not different between WT-OVA mice (black bars) and Barr2 ${ }^{-/-}$-OVA mice (white bars) at day 24. Measurements were made using the endpoint titer method. Data are mean \pm SD calculated from two experiments; $n=3$ mice per group. ND, non-detectable.

\section{Figure 4}

Effect of OVA treatment on serum Ig production. Although OVAspecific $\lg E(\mathbf{a})$ and $\lg G_{1}(\mathbf{b})$ levels changed significantly over time, serum Ig levels in WT-OVA mice (black bars) were not significantly different from those in $\beta a r r 2^{-1-}$-OVA mice (white bars) when compared at each timepoint (days 10,17, and 24). These OVA-specific Ig's were not detected in alum-treated mice of either genotype. Measurements were made using the endpoint titer method. Data are mean \pm SD calculated from two independent experiments; $n=3-8$ mice per group. One-way ANOVA and the Tukey HSD posthoc test were used.

logical measurements made on day 24, when OVA-IgE levels are the same, is unknown. Despite the significant production of OVA-IgE and OVA-IgG ${ }_{1}$ in OVAtreated $\beta a r r 2^{-/-}$mice, the classic features of a Th2mediated asthmatic response, including airway inflammation, airway hyperresponsiveness, and elevated Th2 cytokines, are absent in these mice. Therefore, the defect in the allergic asthmatic response in $\beta a r r 2^{-/-}$mice lies between the generation of a Th2 response and airway inflammation. Our data showing defective $\mathrm{CD}^{+} \mathrm{T}$ cell migration to the Th2 chemoattractant MDC and reduced levels of MDC in lavage fluid suggests that the defect is present at the level of Th2 cell trafficking to the lung.

Other potential mechanisms underlying the phenotype observed in $\beta a r r 2^{-/-}$mice have been evaluated but ruled out. Other studies have shown that enhanced induction of Th1-type cytokines may inhibit the development of a Th2-type response (18). In our study we find no evidence that $\beta a r r 2^{-/-}$ mice experience Th1-type inhibition of their Th2type response since $\operatorname{IgG}_{2 \mathrm{a}}$, IL-12, and IFN- $\gamma$ (factors

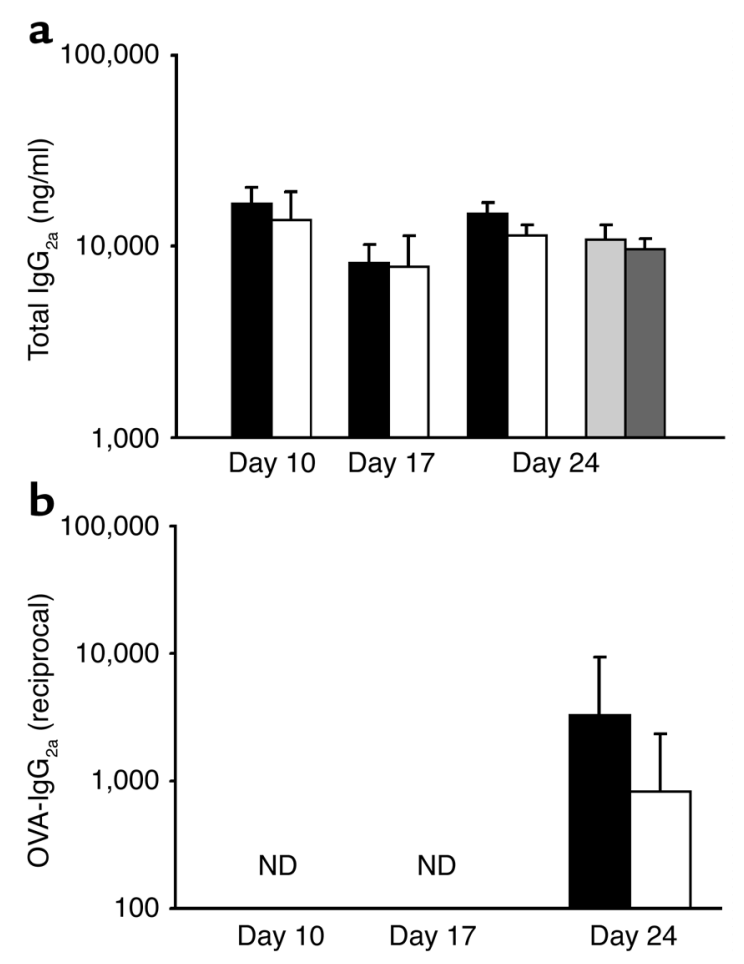




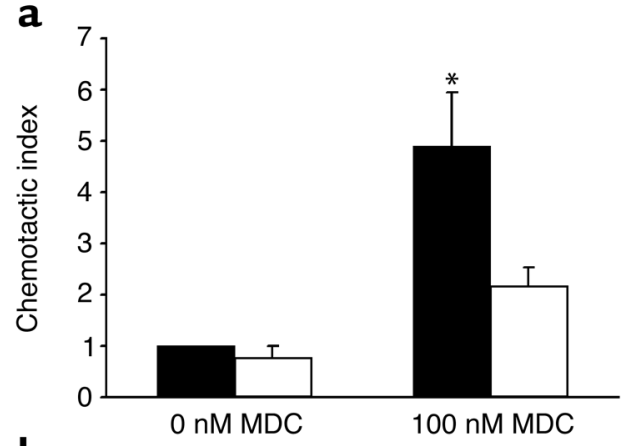

b

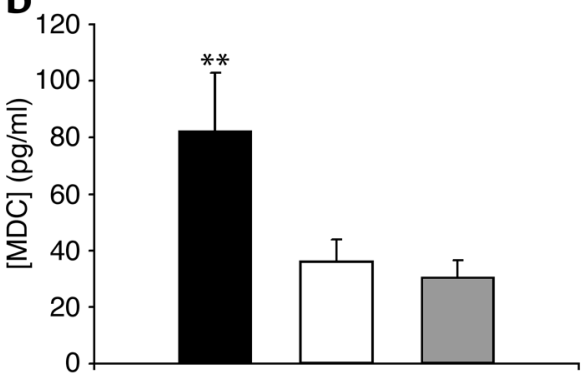

indicative of a Th1 response) are not elevated in $\beta a r r 2^{-/-}$mice relative to WT mice.

Another possible explanation for the failure of Barr 2-/- mice to develop asthma is mast cell dysfunction. Antigen crosslinking of cell-surface IgE receptors stimulates mast cell release of mediators including histamine, prostaglandins, leukotrienes, and cytokines. Collectively, these agents perpetuate airway inflammation and airway hyperresponsiveness and thus appear pivotal to the development of allergic asthma (27). However, the ability to respond to OVA and to develop allergic asthma is preserved in mast cell-deficient mice $(28,29)$. Thus, the failure of Barr2 ${ }^{-/}$mice to develop asthma cannot be explained by mast cell dysfunction.

$T$ cell function is crucial to the development of allergic asthma. When $\mathrm{T}$ cells are nonfunctional or absent, allergic inflammation, airway hyperresponsiveness, and lung cytokine production are prevented in response to OVA treatment (21-23). These results are nearly identical to the dramatically impaired allergic asthmatic response we observed in $\beta a r r 2^{--}$mice. Because $\beta a r r 2^{-/-}$mice have normal levels of $\mathrm{CD}^{+} \mathrm{T}$

\section{Figure 7}

Effect of LPS treatment on airway responsiveness and inflammation. (a) Effect of genotype and LPS treatment on lung inflammation assessed by identification of cells harvested from whole-lung lavage. Black bars represent WT LPS-treated mice; white bars represent $\beta a r r 2^{-/-}$LPS-treated mice. Data are mean \pm SEM; $n=13-15$ mice per group. (b) Airway responsiveness to methacholine, defined by the time-integrated change in peak airway pressure was measured for Barr2 ${ }^{-/-}$(circles) and WT (squares) mice treated with LPS (open symbols) or untreated (filled symbols). Data are mean \pm SEM; $n=13-15$ mice per group. * LPS treatment caused a similar significant increase in APTI in WT and $\beta a r r 2^{-/-}$mice. $P<0.05$.

\section{Figure 6}

Chemotactic responses to MDC and release of MDC in lavage fluid. (a) Lung CD4 ${ }^{+} \mathrm{T}$ cells from OVA-treated $\beta a r r 2^{-/-}$mice (white bars) exhibit decreased migration toward MDC. $C D 4^{+} T$ cells were isolated on day 24 of the OVA treatment protocol and tested for their ability to move chemotactically toward $100 \mathrm{nM} \mathrm{MDC.} \mathrm{Shown}$ is the mean chemotactic index and SE from three independent experiments. ${ }^{*} P<0.05$ vs. $\beta a r r 2^{-1-}$-OVA mice. (b) Release of MDC into whole-lung lavage fluid was significantly induced in OVAtreated WT mice (black bars) but not OVA-treated Barr2-/- mice (white bars). MDC levels in alum-treated WT and alum-treated Barr $2^{-1-}$ mice were not different and therefore were combined (gray bars). Data are mean \pm SEM calculated from two independent experiments; $n=9$ mice per group. ${ }^{*} P<0.05$ versus combined alum-treated mice.

splenocytes (11) and normal architecture of spleen follicles (data not shown), we suggest that $\mathrm{T}$ cell dysfunction, rather than reduction in $\mathrm{T}$ cell number, is at the root of the impaired allergic asthmatic response in $\beta a r r 2^{-/-}$mice. Since the manifestation of allergic asthma requires $\mathrm{T}$ cell proliferation, differentiation, and migration, any one of these processes may be regulated by $\beta$-arrestin- 2 and thus dysregulated in mice completely lacking that protein.

We hypothesize that $\mathrm{T}$ cell migration is the process regulated by $\beta$-arrestin- 2 in allergic asthma. Multiple in vitro reports demonstrate that $\beta$-arrestin regulates chemokine receptor signaling and internalization $(28,30,31)$. Recently, others in our group used the chemokine SDF-1 $\alpha$ (or CXCL12) to show that CXCR4-mediated in vitro migration of nonactivated splenic $\mathrm{T}$ cells is impaired in cells lacking $\beta$-arrestin2 (11). In two separate studies, Gonzalo et al. showed that lung inflammation and airway hyperresponsiveness are significantly reduced when SDF- $1 \alpha$ or MDC are neutralized by antibodies $(32,33)$. Thus, reduced migration of activated T cells to SDF- $1 \alpha$ may

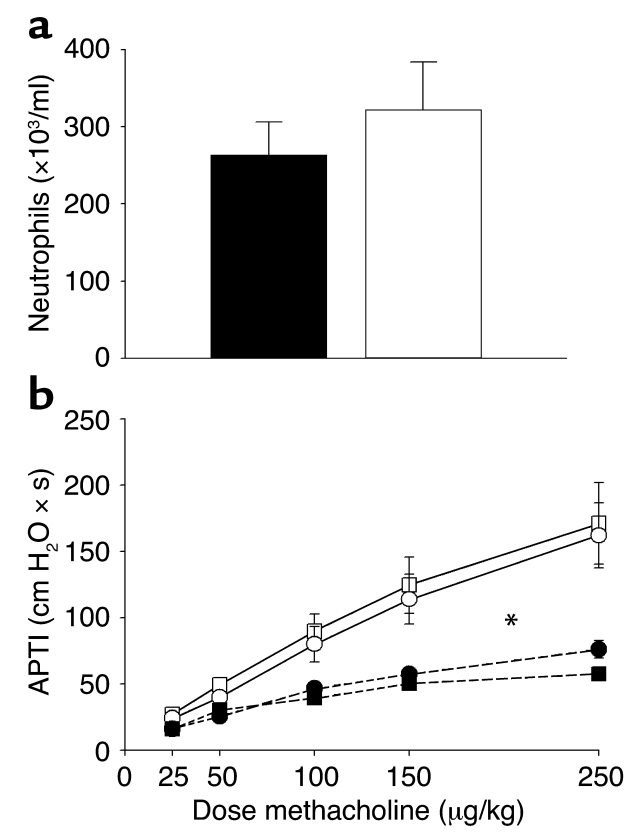


contribute to the phenotype we observed in $\beta a r r 2^{-/-}$ mice. However, in our study, lung SDF- $1 \alpha$ was not significantly induced by OVA treatment in either $\beta$ arr $2^{--}$ or WT mice (data not shown). Thus, MDC is more likely to play a significant role in the development of asthma in our model. Indeed, we showed that not only is the MDC signal reduced in $\beta a r r 2^{-/-}$mice, but the chemotactic response to this signal is also impaired. Thus, $\beta$-arrestin- 2 positively regulates MDC-mediated Th2 cell migration in the context of allergic asthma. We hypothesize that diminished Th 2 cell migration to the lung is the primary impairment in $\beta a r r 2^{-/-}$mice and is largely responsible for their protection against the development of allergic asthma.

The mechanisms by which $\beta$-arrestin- 2 may regulate $\mathrm{T}$ cell chemotaxis in vivo or in vitro are not presently defined. $\beta$-Arrestin proteins act as scaffolds to link GPCR activation to at least three MAPK cascades: the extracellular signal-regulated kinase (ERK) cascade (34), the JNK-3 cascade (35), and the p38 MAPK cascade (12). A recent report indicates that $\beta$-arrestin- 2 activation of the p38 MAPK cascade is required for CXCR4-mediated migration of human embryonic kidney 293 cells to SDF-1 $\alpha$ (12). $\beta$-Arrestin- 2 may similarly regulate CCR4, the receptor for MDC, through mechanisms involving MAPK or other signaling pathways. Although MAPKs regulate the phosphorylation of nuclear transcription factors, recent studies indicate that $\beta$-arrestin-MAPK scaffolds are preferentially targeted to cytosolic substrates (34-36). Such cytosolic substrates may be proteins involved in cell chemotaxis. Thus, $\beta$-arrestin-2, through its action as a scaffold protein, may positively regulate $T$ cell chemotaxis.

Alternatively, in keeping with their classically described role, $\beta$-arrestins may regulate chemotaxis through termination of chemokine receptor signaling (9). This signal termination, or chemokine receptor desensitization, may be crucial to the directional sensing, and thus migration, of $\mathrm{T}$ cells.

Although we feel that $\beta$-arrestin- 2 regulation of $\mathrm{T}$ cell migration is the major mechanism responsible for the profound protection against allergic asthma observed in the $\beta a r r 2^{-/-}$mice, $\beta$-arrestin- 2 regulation of other $\mathrm{T}$ cell functions, or modulation of cells other than lymphocytes, may make a contribution to the dramatic phenotype observed in these mice.

$\beta$-arrestin- 2 could regulate nonhematopoietic cells in the lung such as airway smooth muscle or airway epithelial cells. Indeed, levels of MDC in lavage fluid are reduced in $\beta a r r 2^{-/-}$mice. This may indicate a positive role for $\beta$-arrestin- 2 in regulating chemokine production/secretion by either of these lung cell types. Alternatively, reduced MDC levels in lavage fluid may be explained by altered aeroallergen handling in $\beta a r r 2^{-/-}$mice or may be a by-product of impaired $\mathrm{T}$ cell migration, since Th 2 cells are known to produce MDC. Airway responses to methacholine challenge were not different between $\beta a r r 2^{-/-}$and
WT mice when treated with alum or LPS, suggesting that $\beta$-arrestin- 2 does not regulate airway smooth muscle cell contraction.

$\beta$-arrestin-2 may regulate $\mathrm{T}$ cell differentiation. Yamashita et al. showed that $\mathrm{T}$ cell antigen receptor-mediated activation of the Ras-ERK1/2 pathway enhances IL-4 receptor signaling and is required for the differentiation of naive T cells into Th2 cells (37). Although neither $\mathrm{T}$ cell receptors nor IL-4 receptors are GPCRs, there is evidence in the literature of $\beta$-arrestin-2 modulation of non-GPCR-mediated events through transactivation of nonheptahelical receptors or through intracellular modulation of downstream signaling pathways resulting from antigen or cytokine receptor stimulation (38). Although differentiation of $\mathrm{T}$ cells to the Th2 lineage may be reduced in $\beta a r r 2^{-/-}$ mice, our results suggest that this does not occur during the antigen sensitization phase since the release of IL-4 from Th2 cells is required for the production of allergen-specific IgE by B cells (39) and this function is not impaired in $\beta a r r 2^{-/-}$mice.

The fact that LPS-exposed $\beta a r r 2^{-/-}$mice developed neutrophilic lung inflammation and increased airway responsiveness comparable to similarly treated WT mice demonstrates that there is no universal impairment in inflammatory cell migration in $\beta a r r 2^{--}$mice. This demonstration of a functionally intact innate immune system is critical to the pursuit of $\beta$-arrestin- 2 as a potential therapeutic target for treating allergic asthma.

The absence of $\beta$-arrestin- 2 prevents the development of allergic asthma without compromising the function of the innate immune system. Regulation of $\mathrm{T}$ cell migration to the lung by $\beta$-arrestin- 2 is thought to be the primary mechanism underlying this protection. Because $\beta$-arrestin- 2 exerts its regulatory effect proximal to the recruitment of activated Th2 cells into the lung it is an attractive therapeutic target for treating allergic asthma.

\section{Acknowledgments}

We thank Kris Riebe and Humphrey Kendall for managing the mouse colony. We thank Mike Foster for instruction on aerosol exposure and a critical review of the manuscript. We thank Herman Staats for guidance with respect to the endpoint titer measurement of Ig's. We thank Don Burdick from the Duke University Statistical Consulting Center for advice on statistical analysis. R.J. Lefkowitz is an investigator of the Howard Hughes Medical Institute. These studies were supported by an award to R.J. Lefkowitz from The Sandler Family Supporting Foundation and by NIH grants CA-098110 to D.D. Patel and P50 ES-09607, R01 ES-07498, and U01 HL-66611 to D.A. Schwartz.

\footnotetext{
1. Wills-Karp, M. 1999. Immunologic basis of antigen-induced airway hyperresponsiveness. Annu. Rev. Immunol. 17:255-281.

2. Ray, A., and Cohn, L. 1999. Th2 cells and GATA-3 in asthma: new insights into the regulation of airway inflammation. J. Clin. Invest. 104:985-993.

3. National Institutes of Health. 1995. Data fact sheet: asthma statistics.
} 
Report number 55-798. National Heart Lung and Blood Institute. Washington, DC, USA. 1-4

4. Sallusto, F., Mackay, C.R., and Lanzavecchia, A. 2000. The role of chemokine receptors in primary, effector, and memory immune responses. Annu. Rev. Immunol. 18:593-620.

5. Lloyd, C. 2002. Chemokines in allergic lung inflammation. Immunology. 105:144-154.

6. Probst, W.C., Snyder, L.A., Schuster, D.I., Brosius, J., and Sealfon, S.C. 1992. Sequence alignment of the G-protein coupled receptor superfamily. DNA Cell Biol. 11:1-20.

7. Attramadal, H., et al. 1992. Beta-arrestin2, a novel member of the arrestin/beta-arrestin gene family. J. Biol. Chem. 267:17882-17890.

8. Miller, W.E., and Lefkowitz, R.J. 2001. Expanding roles for betaarrestins as scaffolds and adapters in GPCR signaling and trafficking. Curr. Opin. Cell Biol. 13:139-145.

9. Pierce, K.L., and Lefkowitz, R.J. 2001. Classical and new roles of betaarrestins in the regulation of G-protein-coupled receptors. Nat. Rev Neurosci. 2:727-733.

10. Benovic, J.L., et al. 1987. Functional desensitization of the isolated beta-adrenergic receptor by the beta-adrenergic receptor kinase: potential role of an analog of the retinal protein arrestin (48-kDa protein). Proc. Natl. Acad. Sci. U. S. A. 84:8879-8882.

11. Fong, A.M., et al. 2002. A positive regulatory role for the $\beta$-arrestinGRK system in lymphocyte chemotaxis. Proc. Natl. Acad. Sci. U. S. A. 99:7478-7483

12. Sun, Y., Cheng, Z., Ma, L., and Pei, G. 2002. Beta-arrestin2 is critically involved in CXCR4-mediated chemotaxis and this is mediated by its enhancement of p38 MAPK activation. J. Biol. Chem. 277:49212-49219.

13. Leong, K.P., and Huston, D.P. 2001. Understanding the pathogenesis of allergic asthma using mouse models. Ann. Allergy Asthma Immunol. 87:96-110.

14. Bohn, L.M., et al. 1999. Enhanced morphine analgesia in mice lacking beta-arrestin 2. Science. 286:2495-2498.

15. Lorenz, E., et al. 2001. Genes other than TLR4 are involved in the response to inhaled LPS. Am. J. Physiol. Lung Cell Mol. Physiol. 281:L1106-L1114.

16. Walker, J.K., Peppel, K., Lefkowitz, R.J., Caron, M.G., and Fisher, J.T. 1999. Altered airway and cardiac responses in mice lacking $\mathrm{G}$ proteincoupled receptor kinase 3. Am. J. Physiol. 276:R1214-R1221.

17. Levitt, R.C., and Mitzner, W. 1988. Expression of airway hyperreactivity to acetylcholine as a simple autosomal recessive trait in mice. FASEB J. 2:2605-2608.

18. Eisenbarth, S.C., et al. 2002. Lipopolysaccharide-enhanced, toll-like receptor 4-dependent $T$ helper cell type 2 responses to inhaled antigen. J. Exp. Med. 196:1645-1651.

19. Bone, R.C. 1991. Gram-negative sepsis. Background, clinical features, and intervention. Chest. 100:802-808.

20. Deetz, D.C., et al. 1997. The kinetics of grain dust-induced inflammation of the lower respiratory tract. Am. J. Respir. Crit. Care Med. 155:254-259.

21. Corry, D.B., et al. 1998. Requirements for allergen-induced airway hyperreactivity in T and B cell-deficient mice. Mol. Med. 4:344-355. 22. Garlisi, C.G., et al. 1995 . T cells are necessary for Th2 cytokine pro- duction and eosinophil accumulation in airways of antigen-challenged allergic mice. Clin. Immunol. Immunopathol. 75:75-83.

23. Gavett, S.H., Chen, X., Finkelman, F., and Wills-Karp, M. 1994. Depletion of murine CD4+ T lymphocytes prevents antigen-induced airway hyperreactivity and pulmonary eosinophilia. Am.J. Respir. Cell Mol. Biol. 10:587-593.

24. Watts, C. 1997. Capture and processing of exogenous antigens for presentation on MHC molecules. Annu. Rev. Immunol. 15:821-850.

25. Garside, P., et al. 1998. Visualization of specific B and T lymphocyte interactions in the lymph node. Science. 281:96-99.

26. Jelinek, D.F. 2000. Regulation of B lymphocyte differentiation. Ann. Allergy Asthma Immunol. 84:375-387.

27. Metcalfe, D.D., Baram, D., and Mekori, Y.A. 1997. Mast cells. Physiol. Rev. 77:1033-1079.

28. Kobayashi, T., et al. 2000. An essential role of mast cells in the development of airway hyperresponsiveness in a murine asthma model. J. Immunol. 164:3855-3861.

29. Takeda, K., et al. 1997. Development of eosinophilic airway inflammation and airway hyperresponsiveness in mast cell-deficient mice. J. Exp. Med. 186:449-454.

30. Cheng, Z.J., et al. 2000. beta-Arrestin differentially regulates the chemokine receptor CXCR4-mediated signaling and receptor internalization, and this implicates multiple interaction sites between betaarrestin and CXCR4. J. Biol. Chem. 275:2479-2485.

31. Kraft, K., et al. 2001. Characterization of sequence determinants within the carboxyl-terminal domain of chemokine receptor CCR5 that regulate signaling and receptor internalization. J. Biol. Chem. 276:34408-34418.

32. Gonzalo, J.A., et al. 1999. Mouse monocyte-derived chemokine is involved in airway hyperreactivity and lung inflammation. J. Immunol. 163:403-411.

33. Gonzalo, J.A., et al. 2000. Critical involvement of the chemotactic axis CXCR4/stromal cell-derived factor- 1 alpha in the inflammatory component of allergic airway disease. J. Immunol. 165:499-508.

34. Luttrell, L.M., et al. 2001. Activation and targeting of extracellular signal-regulated kinases by beta-arrestin scaffolds. Proc. Natl. Acad. Sci.U. S. A. 98:2449-2454.

35. McDonald, P.H., et al. 2000. Beta-arrestin 2: a receptor-regulated MAPK scaffold for the activation of JNK3. Science. 290:1574-1577.

36. Tohgo, A., Pierce, K.L., Choy, E.W., Lefkowitz, R.J., and Luttrell, L.M 2002. beta-Arrestin scaffolding of the ERK cascade enhances cytosolic ERK activity but inhibits ERK-mediated transcription following angiotensin AT1a receptor stimulation. J. Biol. Chem. 277:9429-9436.

37. Yamashita, M., et al. 1999. T cell antigen receptor-mediated activation of the Ras/mitogen-activated protein kinase pathway controls interleukin 4 receptor function and type- 2 helper T cell differentiation. Proc. Natl. Acad. Sci. U. S. A. 96:1024-1029.

38. Johnson, E.N., and Druey, K.M. 2002. Heterotrimeric G protein signaling: role in asthma and allergic inflammation. J. Allergy Clin. Immunol. 109:592-602.

39. Nelms, K., Keegan, A.D., Zamorano, J., Ryan, J.J., and Paul, W.E. 1999. The IL-4 receptor: signaling mechanisms and biologic functions. Annu. Rev. Immunol. 17:701-738. 